\title{
The Neotropical caddisfly genus Canoptila (Trichoptera: Glossosomatidae)
}

\author{
DESIREE R. ROBERTSON ${ }^{1} \&$ RALPH W. HOLZENTHAL ${ }^{2}$ \\ University of Minnesota, Department of Entomology, 1980 Folwell Ave., Room 219, St. Paul, Minnesota \\ 55108, U.S.A.E-mail: ${ }^{1}$ robe0494@umn.edu; ${ }^{2}$ holze001@umn.edu
}

\begin{abstract}
The caddisfly genus Canoptila Mosely (Glossosomatidae: Protoptilinae), endemic to southeastern Brazil, is diagnosed and discussed in the context of other protoptiline genera, and a brief summary of its taxonomic history is provided. A new species, Canoptila williami, is described and illustrated, including a female, the first known for the genus. Additionally, the type species, Canoptila bifida Mosely, is redescribed and illustrated. There are three possible synapomorphies supporting the monophyly of Canoptila: 1) the presence of long spine-like posterolateral processes on tergum X;2) the highly membranous digitate parameres on the endotheca; and 3) the unique combination of both forewing and hind wing venational characters.
\end{abstract}

Key words: Trichoptera, Glossosomatidae, Protoptilinae, Canoptila, new species, caddisfly, male genitalia, female genitalia, Neotropics, Atlantic Forest, southeastern Brazil

\section{INTRODUCTION}

The Atlantic Forest of southeastern Brazil is well known for its highly endemic flora and fauna, and has been designated a biodiversity hotspot (da Fonseca 1985; Myers et al. 2000). The forest, consisting of tropical evergreen and semideciduous mesophytic broadleaf species, originally covered most of the slopes of the coastal mountains and extended from well inland to the coastline (Fig. 6) (da Fonseca 1985). Today it is the most heavily populated region in Brazil and experts estimate that anywhere between less than 1-7.5\% of original primary forest remains (da Fonseca 1985; Myers et al. 2000). Despite this extreme deforestation, many new species and even new genera are still being discovered in the region; approximately 300 new species of caddisflies from the region await description at the University of Minnesota Insect Collection.

Based on current distribution records, 5 endemic caddisfly genera are known from the 

Anastomoneura Huamantinco \& Nessimian 2004, Altarosa Blahnik 2005, and the focus of this paper, Canoptila Mosely 1939.

Previously, the genus Canoptila contained a single species, C. bifida Mosely, known only from Nova Teutônia, Brazil. As a result of a recent survey of southeastern Brazil by researchers at the University of Minnesota in collaboration with colleagues at the Pontifícia Universidade Católica de Minas Gerais and Universidade de São Paulo Ribeirão Preto, a new species is described herein, including the first description of a female for the genus. Additionally, $C$. bifida is redescribed and illustrated and a discussion of the systematic position of the genus is included.

\section{MATERIAL AND METHODS}

Morphological terminology used for male genitalia has been adapted from Holzenthal \& Blahnik (2006) and Morse $(1975 ; 1988)$. For female genitalia, we use the terminology of Nielson (1980). For setal warts of the head and thorax, terminology from Wiggins (1996) is used. Terminology for wing venation follows that established by Robertson \& Holzenthal (2005). Procedures for specimen preparation, examination, and illustrations, as well as construction of species descriptions, followed those explained in detail by Holzenthal \& Andersen (2004). Each individual specimen examined, or lot of specimens if preserved in alcohol, contains a barcode label with a unique 9 digit accession number beginning with the prefix "UMSP." The prefix is not meant to imply possession by the University of Minnesota Insect Collection, but only to indicate that the specimen is databased at that collection. Specimen barcode accession numbers are included in the list of material examined for holotypes, but not for paratypes. A list of all specimens examined for this study, including taxonomic, locality, collection, storage and individual specimen barcode information can be accessed at the UMSP Trichoptera Biota ${ }^{\circledR}$ database, www.entomology.umn.edu/museum/databases/BIOTAdatabase.html.

Types of the species described here and other material examined are deposited, as indicated in the species descriptions, in the following institutions:

BMNH Natural History Museum, London, England

MZUSP Museu de Zoologia, Universidade de São Paulo, São Paulo, Brazil

NMNH National Museum of Natural History, Smithsonian Institution, Washington, DC, USA

UMSP University of Minnesota Insect Collection, Saint Paul, Minnesota, USA 
Position of Canoptila within the subfamily Protoptilinae

Canoptila Mosely, is a member of the saddle-, or tortoise-case making caddisfly family Glossosomatidae. Mosely (1939) first described the genus in Hydroptilidae, but later transferred it to what he referred to as the "Protoptila group" in Glossomatinae, which at that time was a subfamily within Rhyacophilidae (Mosely 1954). The "Protoptila group" also included Antoptila Mosely 1939 (junior synonym of Itauara Müller 1888), Mexitrichia Mosely 1937, Mortoniella Ulmer 1906, and Protoptila Banks 1904. In 1956, Ross elevated these allied genera to subfamily status, the Protoptilinae, within Glossosomatidae. There are now 18 recognized protoptiline genera.

Several workers have discussed some possible relationships among protoptiline genera (Angrisano 1993; Flint 1964; Ross 1956; Schmid 1990; Morse \& Yang 1993; Robertson \& Holzenthal 2005, among others), but a phylogeny has yet to be published. However, a few general observations can be made about the possible affinities of Canoptila to other protoptiline genera.

Canoptila shares some derived characters with several other Protoptilinae genera. In the forewing (Fig. 2A), Canoptila has lost apical forks IV and V and the A3 vein, and Cu1 and $\mathrm{Cu} 2$ have fused above the wing margin forming a continuous vein. This condition is also present in Itauara, Campsiophora Flint 1964, Cubanoptila Sykora 1973 (in Botosaneanu \& Sykora 1973), and Mastigoptila Flint 1967. In the hind wing (Fig. 2B), Canoptila shares the loss of forks I, III, IV, and V, and the loss of A2 with the genera Scotiotrichia Mosely 1934, Protoptila, and some species of Mexitrichia. On the mesothorax of Canoptila (Fig. 1B), arising from beneath the tegula, are paired telescopic glandular projections, that appear to be eversible. Culoptila Mosely 1954 has similar structures, although much larger and "concertina-shaped," indicating another possible relationship with Canoptila, but it is unclear if these are indeed homologous structures. Further examination is needed to determine if any other protoptilines possess these novel tegular structures. These characters suggest that Canoptila is perhaps most closely related to the more derived protoptiline genera. A modern phylogenetic analysis of all protoptiline genera will better help our understanding of these relationships.

There are 3 possible synapomorphies supporting the monophyly of Canoptila. Firstly, is the presence of long spine-like posterolateral processes on tergum X. Secondly, is the highly membranous digitate parameres on the endotheca. Primitively, parameres are more elongate and rodlike (Schmid 1989); the condition observed in Canoptila, highly membranous digitate parameres with the sclerotized apices, appears to be derived. Finally, the unique combination of both forewing and hind wing venational characters, as discussed above, is a possible synapomorphy of the genus. 
Canoptila Mosely, 1939: 218 [Type species: Canoptila bifida Mosely 1939, original designation].

The genus Canoptila can be identified by the general shape of tergum X, the pair of long spine-like processes arising from the posterolateral margins of tergum $\mathrm{X}$, and the paired, highly membranous digitate parameres basoventrally on the endotheca of the male genitalia. Forewing venation (Fig. 2A) of Canoptila is typical of many other protoptilines in that $\mathrm{Cu} 1$ and $\mathrm{Cu} 2$ intersect one another, forming a somewhat continuous vein. The genus is most similar in forewing venation to Campsiophora, Cubanoptila, Itauara, and Mastigoptila, based on the presence of apical forks I, II, and III, and the loss of A3 in the forewing. However, Canoptila can be distinguished from these genera by the length of its apical forks; fork I emerging at the cord and forks II and III emerging closer to the wing apex. The hind wing venation of Canoptila is similar to the genera Campsiophora, Cariboptila Flint 1964, and some species of Mexitrichia in that these genera all possess apical fork II only, but differ in the anal veins: Canoptila has a single vein, whereas the other genera have retained A2. The paired telescopic, glandular projections arising from beneath the tegulae are reminiscent of similar structures in Culoptila. However in Culoptila these structures are "concertina-shaped" (Mosely 1954) and appear to emerge more posterolaterally, whereas in Canoptila they are tubular and anterior in position. The two genera can also be easily differentiated based on their wing venation and male genitalia.

Adult. Forewing length: male $2.5-3.0 \mathrm{~mm}$; female $2.6-3.2 \mathrm{~mm}$. Body, wings, and appendages nearly uniformly fuscous or tawny-brown, tibia and tarsi yellowish brown. Head (Fig. 1A) broader than long, vertex rounded, with large anteromesal setal wart, 2 pairs of suboval anterior setal warts, small oval posterior setal warts, and large subtriangular posterolateral setal warts. Ocelli present. Antennal scape long, about $2 \mathrm{x}$ the length of pedicel. Maxillary palps 5 segmented, $1^{\text {st }}$ and $2^{\text {nd }}$ segments short with elongate setae apically; $2^{\text {nd }}$ segment bulbous; last 3 segments each nearly same length as $1^{\text {st }}$ and $2^{\text {nd }}$ segments combined. Prothorax with 2 large subtriangular pronotal setal warts. Mesothorax (Fig. 1B), with paired telescopic glandular structure arising basoventrally from the tegula. This tegular structure was easily visible on 2 alcohol preserved specimens of $C$. bifida; similar structures were observed on a single fully cleared specimen of $C$. williami, new species, but appeared to be fully invaginated, inside the mesothorax and therefore quite difficult to see. Mesoscutum with 2 pairs of setal warts, small anteromesal pair and suboval posterolateral pair; mesoscutellum sparsely setose. Forewing (Fig. 2A) narrow, margins nearly parallel, apex oblique, with row of erect setae slightly below $\mathrm{Cu} 2$. Forewing venation incomplete, apical forks I, II, and III present; fork I emerging at cord; forks II and III shorter than their stems; Sc and R1 distinct along their entire lengths; Sc reaching anterior margin; $\mathrm{Cu} 1$ and $\mathrm{Cu} 2$ intersecting near cord, forming a seemingly continuous vein, apical part of $\mathrm{Cu} 2$ turning sharply downward to meet the wing margin at 
or apicad of intersection; A3 absent; crossveins $r, d, r-m$, and $m$-cu present, forming a relatively linear transverse cord. Hind wing (Fig. 2B) narrow, tapering slightly past anastomosis, subacute apically; apical fork II present; Sc and R1 fused basally; crossveins not visible. Tibial spurs $1,4,4$, foretibial spur similar to other protoptiline genera, being extremely reduced and hair-like as illustrated in Robertson \& Holzenthal (2005).
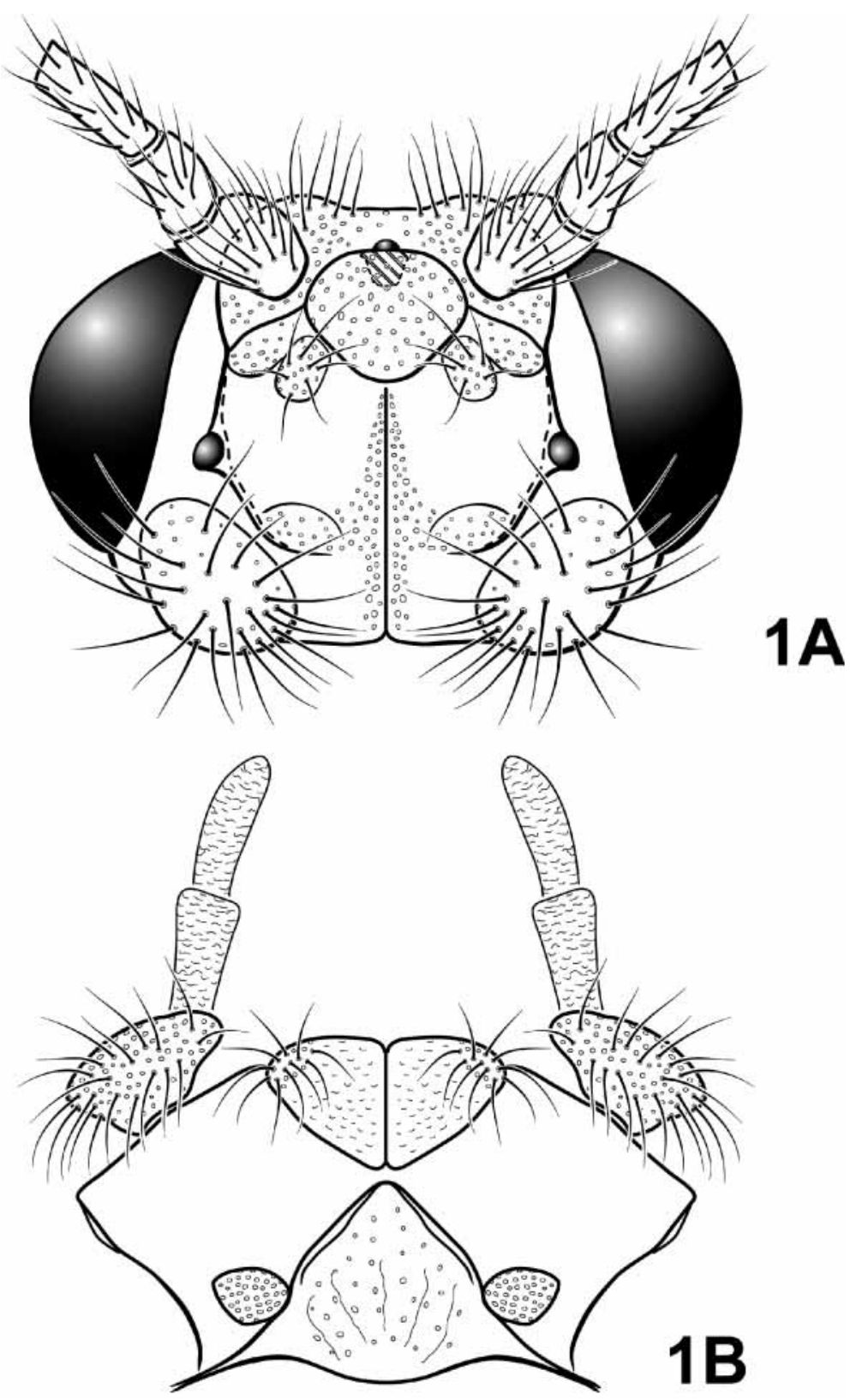

FIGURE 1. Canoptila bifida Mosely (UMSP000210904). Adult: A. dorsal view of head; B. dorsal view of mesothorax. 
Male genitalia (Figs. 3,4). Sternum VI with thin digitate mesal process, associated with weak, oblique apodeme posteriorly. Preanal and inferior appendages absent. Abdominal segment IX well developed, with both tergum and sternum. Tergum IX fused to tergum X. Tergum IX in lateral view, forming truncate ridge apicodorsally; in dorsal view, posterior margin rounded or subtriangular, covered in fine microtrichia. Tergum $\mathrm{X}$ emerging below ridge of tergum IX, apex rounded or subtruncate, setose dorsally, apically, and ventrally, with pair of long spine-like processes arising from posterolateral margin, directed inward; in dorsal view, bifid or subquadrate, anterior margin slightly irregular. Phallocrypt extending from beneath tergum $X$ to ventral region of segment IX, entirely membranous except for lightly sclerotized phallic shield where phallic apparatus is attached. Phallobase reduced, lightly sclerotized, with paired row or patches of setae ventrolaterally. Endotheca membranous, basoventrally bearing pair of membranous digitate processes with sclerotized or asperous apices (based on their position arising from the endotheca and preceding the phallicata, these structures are hypothesized to be homologous to parameres). Endophallus highly membranous, enlarged and convoluted when evaginated, bearing 1 to several pairs of large, pointed, sclerotized processes, lightly sclerotized apically or with terminal sclerite.

Female genitalia (Fig. 5). Truncate posteriorly. Sternum VI process thin, projecting caudally, without apparent associated apodeme. Abdominal segment VIII syncleritous, relatively short. Segments IX and X closely associated, with pair of small digitate cerci dorsolaterally.

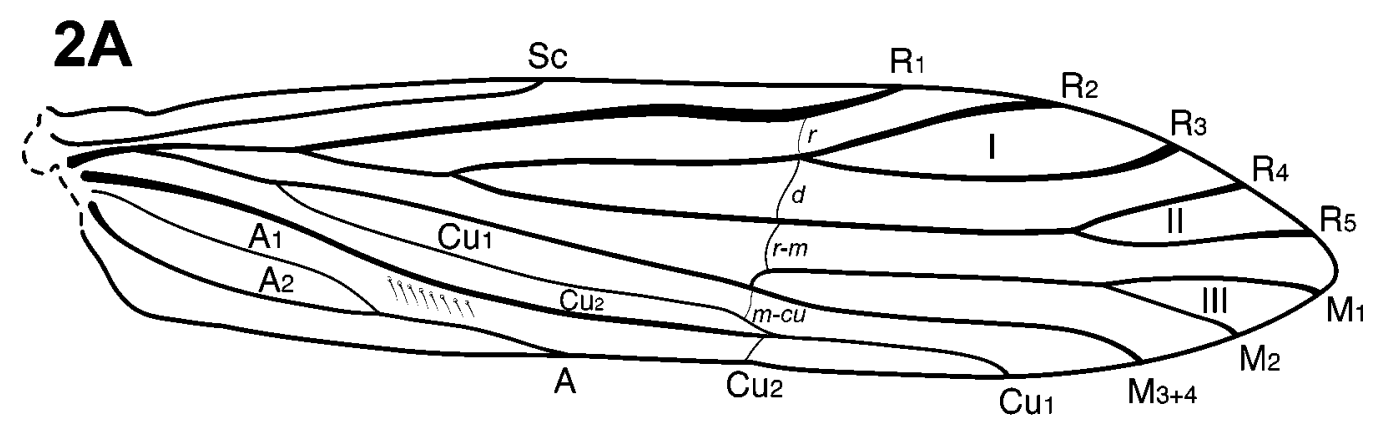

\section{B}

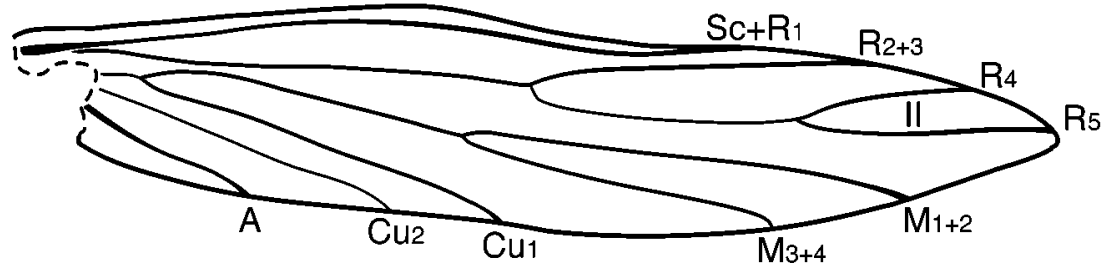

FIGURE 2. Canoptila bifida Mosely_holotype (UMSP000107591). Wings: A. forewing; B. hind wing. 
The female is known only from $C$. williami, new species, so it is unclear as to whether female characters identified here are species specific or typical of the genus.

\section{Included species}

Canoptila bifida Mosely, Canoptila williami, new species.

\section{SPECIES DESCRIPTIONS}

\section{Canoptila bifida Mosely}

(Figs. 1-3)

Canoptila bifida Mosely, 1939: 218 [Type locality: Brazil, Santa Catarina, Nova Teutônia; BMNH; male].

Canoptila bifida can be distinguished from $C$. williami, new species, by the shape of abdominal segment IX, which is much broader laterally. Tergum $\mathrm{X}$ is triangular in lateral view in C. bifida and quadrate in C. williami. In C. bifida, tergum X is also bifid in dorsal view, while it is subquadrate in the new species. The dorsomesal processes on the endotheca are much more heavily sclerotized and prominent in $C$. bifida than in $C$. williami, while the basolateral digitate parameres are smaller. In the forewing of $C$. bifida, the apical part of $\mathrm{Cu} 2$ turns sharply downward to meet the wing margin at the intersection of $\mathrm{Cu} 1$ and $\mathrm{Cu} 2$, whereas in $C$. williami, it turns down distad of this intersection.

Adult male. Length of forewing: 2.7-3.0 mm ( $n=4)$. Body, wings, and appendages tawny, legs and base of antennae yellowish brown. Wings (Figs. 2A, 2B) as detailed in the generic diagnosis.

Male genitalia (Fig. 3). Sternum VI (Fig. 3A) with thin, digitate mesal process, projecting caudally. Abdominal segment IX (Fig. 3B) broadest laterally, anterior margin sinuous. Tergum IX in lateral view (Fig. 3B), with anterior margin sinuous, forming truncate ridge apicodorsally; in dorsal view (Fig. 3C), with posterior margin rounded, covered in fine microtrichia. Tergum $\mathrm{X}$ in lateral view (Fig. 3B), triangular, ventral margin smooth, sloping downward, setose dorsally, apically, and ventrally, apex rounded; in dorsal view (Fig. 3C), bifid, lightly sclerotized laterally, membranous mesally, with pair of long spine-like processes arising from posterolateral margin at right angle, curved inward. Phallocrypt (Fig. 3B) extending from beneath tergum $X$ to ventral region of segment IX, entirely membranous except for lightly sclerotized phallic shield where phallic apparatus is attached. Phallobase (Figs. 3B, 3D) reduced, lightly sclerotized, with paired row of setae ventrolaterally. Endotheca (Figs. 3B, 3D) membranous, basoventrally bearing pair of small, membranous digitate parameres with small apical sclerite. Endophallus (Figs. 3B, 3D) highly membranous, enlarged and convoluted when evaginated; dorsomesally bearing pair of large, heavily sclerotized, bifid processes, their 
Female unknown.
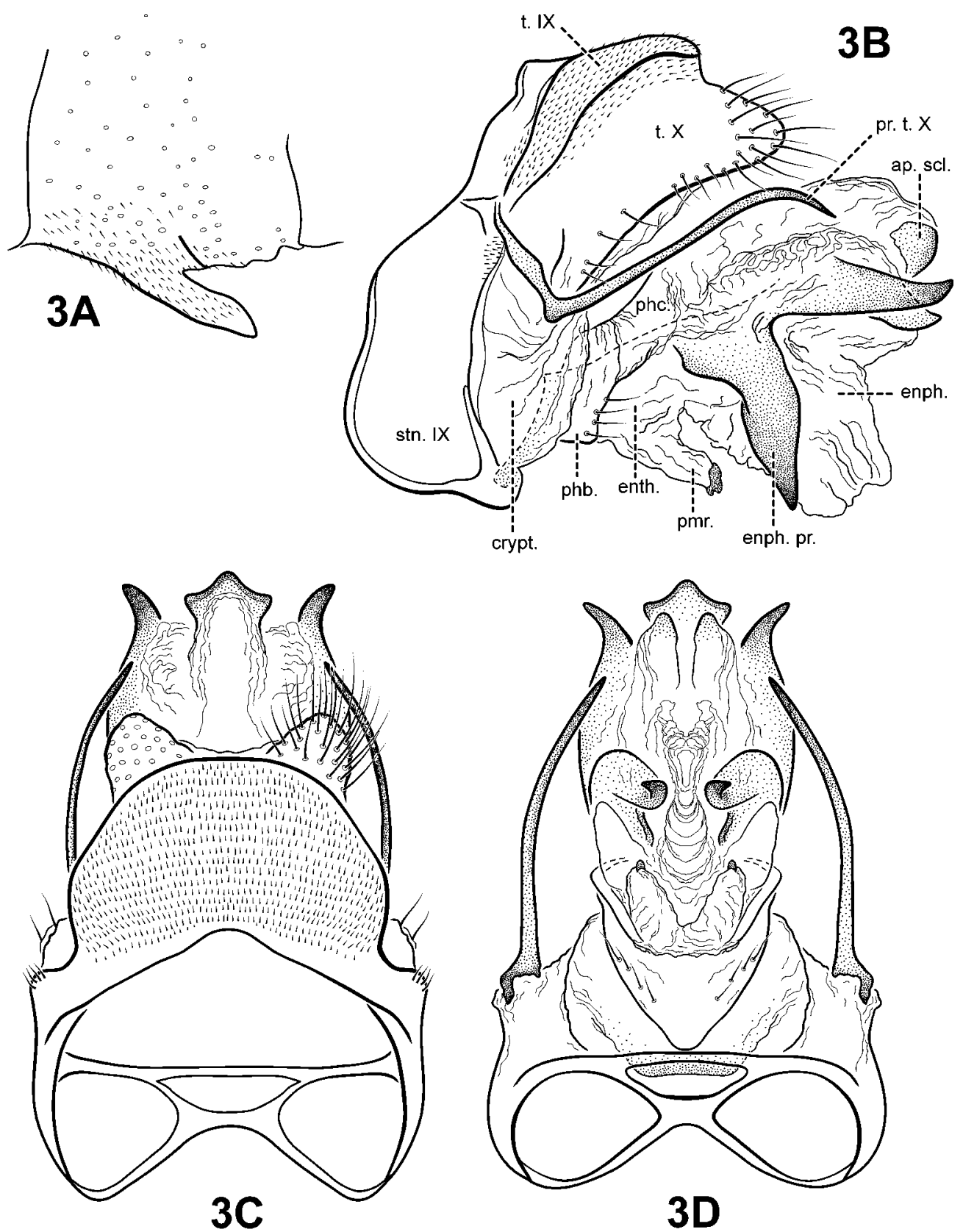

FIGURE 3. Canoptila bifida Mosely (composite of UMSP000210904 \& UMSP000211376). Male: A. process of sternum VI, lateral; B. genitalia, lateral; C. genitalia, dorsal; D. genitalia, ventral. Abbreviations: ap.scl. $=$ apical sclerite; crypt $=$ phallocrypt $;$ enph.$=$ endophallus; enph. pr. $=$ endophallic process; enth. $=$ endotheca; phb $=$ phallobase; phc. $=$ phallicata; pmr. $=$ paramere; pr. t. $X=$ process of tergum $X$; stn. IX = sternum IX; t. IX = tergum IX; t. $X=$ tergum $X$. 
Material examined: BRAZIL: Santa Catarina: Seara (Nova Teutônia), 27¹1'00"S, 052 $23^{\circ} 00 " \mathrm{~W}, 300-500 \mathrm{~m}, 1 . x i i .1937$, Plaumann—1 male (holotype) (UMSP000107591)

(BMNH); same except 1.i.1963, Plaumann-2 males (NMNH); same except 1.x.1964, Plaumann- 1 male (NMNH).

Distribution. Brazil. This species is known only from the Atlantic Forest in southeastern Brazil.

\section{Canoptila williami, new species}

(Figs. 4,5)

Abdominal segment IX in Canoptila williami is narrower laterally and ventrally than in $C$. bifida. Tergum $\mathrm{X}$ in lateral view is quadrate in C. williami and triangular in C. bifida. In the new species tergum $\mathrm{X}$ is subquadrate in dorsal view while it is bifid in C. bifida. On the endotheca, $C$. williami has larger parameres, and smaller, less sclerotized dorsomesal processes than $C$. bifida. In the forewing of $C$. williami, the apical part of $\mathrm{Cu} 2$ turns sharply downward to meet the wing margin apicad of the intersection of $\mathrm{Cu} 1$ and $\mathrm{Cu} 2$, instead of at the intersection as in C. bifida.

Adult. Length of forewing: male 2.5-3.0 mm ( $n=5)$; female 2.6-3.2 mm ( $n=4)$. Body, wings, and appendages nearly uniformly fuscous, tibia and tarsi yellowish brown. Wings (Figs. 2A, 2B) as detailed in the generic diagnosis, except apical part of $\mathrm{Cu} 2$, turning sharply down to meet the wing margin apicad of the intersection of $\mathrm{Cu} 1$ and $\mathrm{Cu} 2$.

Male genitalia (Fig. 4). Sternum VI (Fig. 4A) with thin, digitate mesal process, projecting caudally. Abdominal segment IX (Fig. 4B) well developed dorsally, narrow laterally and ventrally, anterior margin nearly straight. Tergum IX in lateral view (Fig. 4B), with anterior margin straight, forming truncate ridge apicodorsally; in dorsal view (Fig. 4C), posterior margin subtriangular, covered in fine microtrichia. Tergum $X$ in lateral view (Fig. 4B), quadrate, posterior and ventral margins irregular, setose dorsally, apically, and ventrally, apex subtruncate; in dorsal view (Fig. 4C), subquatrate, slightly irregular, with pair of long, straight, spine-like processes arising from posterolateral margin and forming an apparent articulation, directed inward. Phallocrypt (Fig. 4B) extending from beneath tergum $\mathrm{X}$ to ventral region of segment IX, entirely membranous except for lightly sclerotized phallic shield where phallic apparatus is attached. Phallobase (Figs. 4B, 4D) reduced, lightly sclerotized, with paired patches of setae ventrolaterally. Endotheca (Figs. 4B, 4D) membranous, basoventrally bearing pair of large, membranous digitate parameres with large globular, asperous apices. Endophallus (Figs. 4B, 4D) highly membranous, enlarged and convoluted when evaginated; apicomesally, bearing single pair of sharply pointed, sclerotized processes; apicodorsally, bifid, with membranous upper lobe, lightly sclerototized lower lobe. 

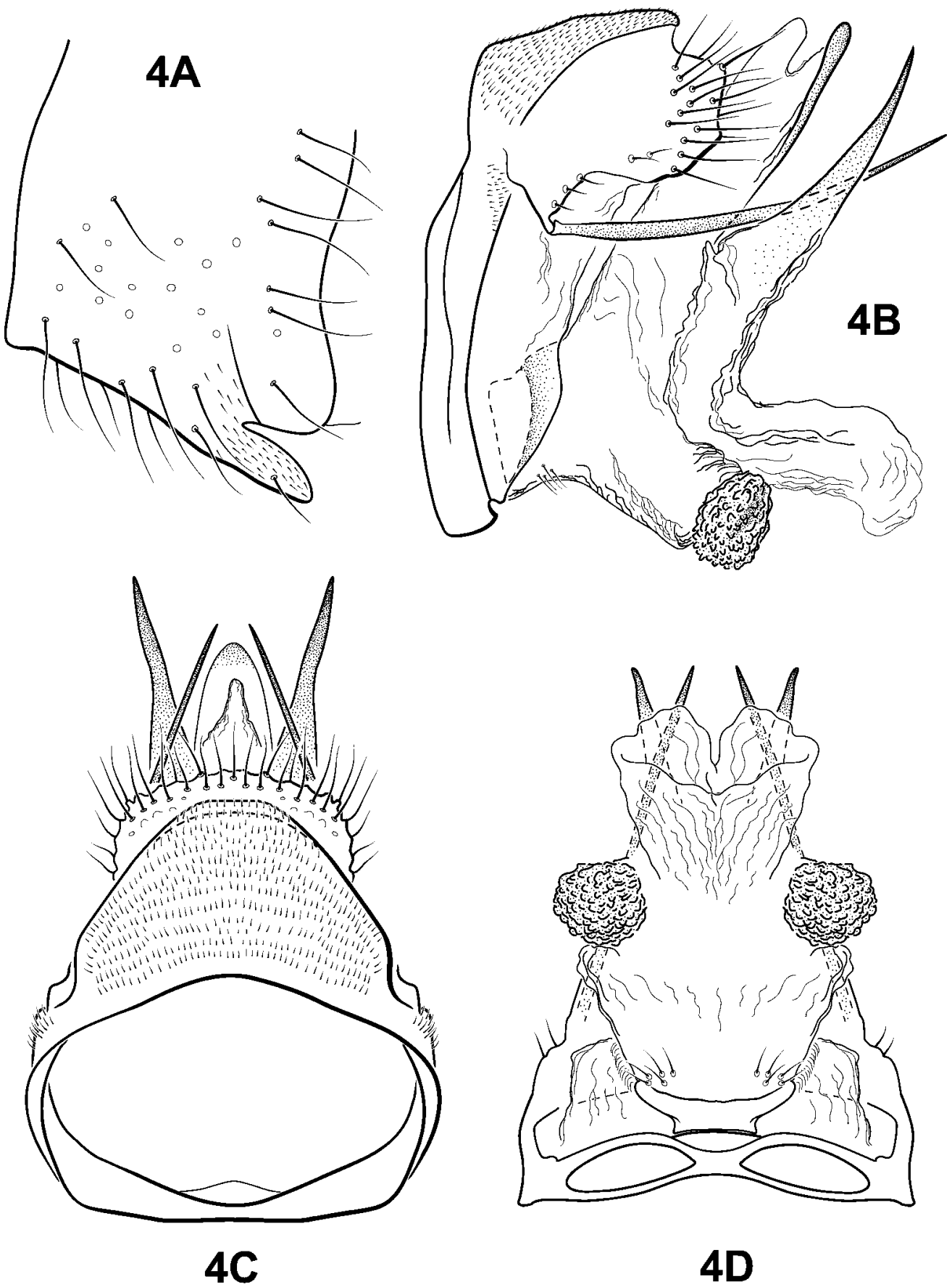

FIGURE 4. Canoptila williami n. sp. (UMSP 000087912). Male: A. process of sternum VI; B. genitalia, lateral; C. genitalia, dorsal; D. genitalia, ventral. 

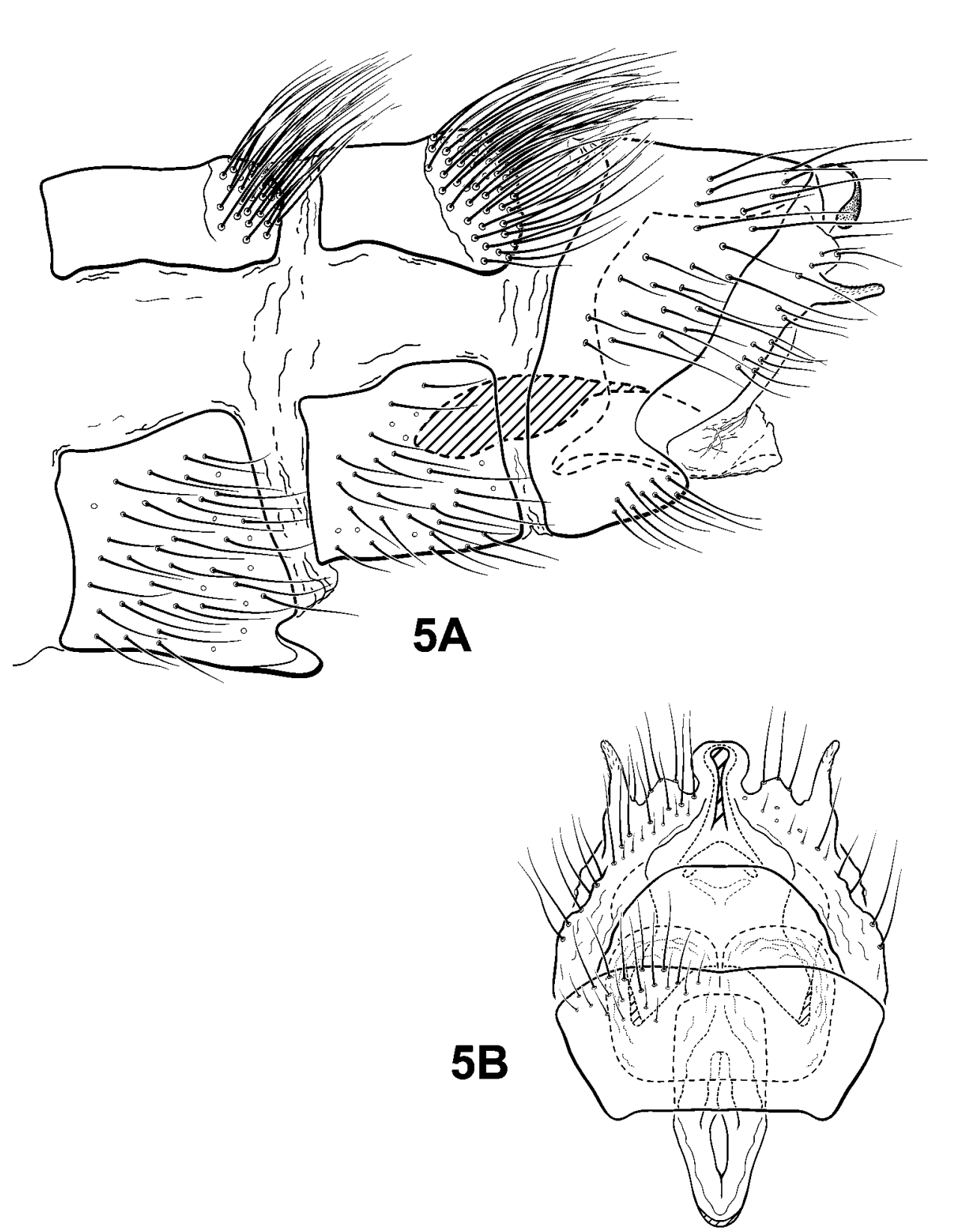

FIGURE 5. Canoptila williami n. sp. (UMSP000029632). Female genitalia: A. lateral, B. ventral.

Female genitalia (Figs. 5A \& 5B). Sternum VI with thin digitate mesal process, projecting caudally. Tergum VI and VII with patches of long, bristle-like setae posteriorly. Abdominal segment VIII synscleritous, relatively short. Segments IX and X closely associated to the point that their boundaries cannot be discerned with any certainty, with pair of small digitate cerci dorsolaterally. Genital chamber lightly sclerotized, short, extending to anterior end of segment VIII, with pair of membranous lobes ventrally. Vaginal apparatus sclerotized; in lateral view (Fig. 5A), suboval, with slender process at 


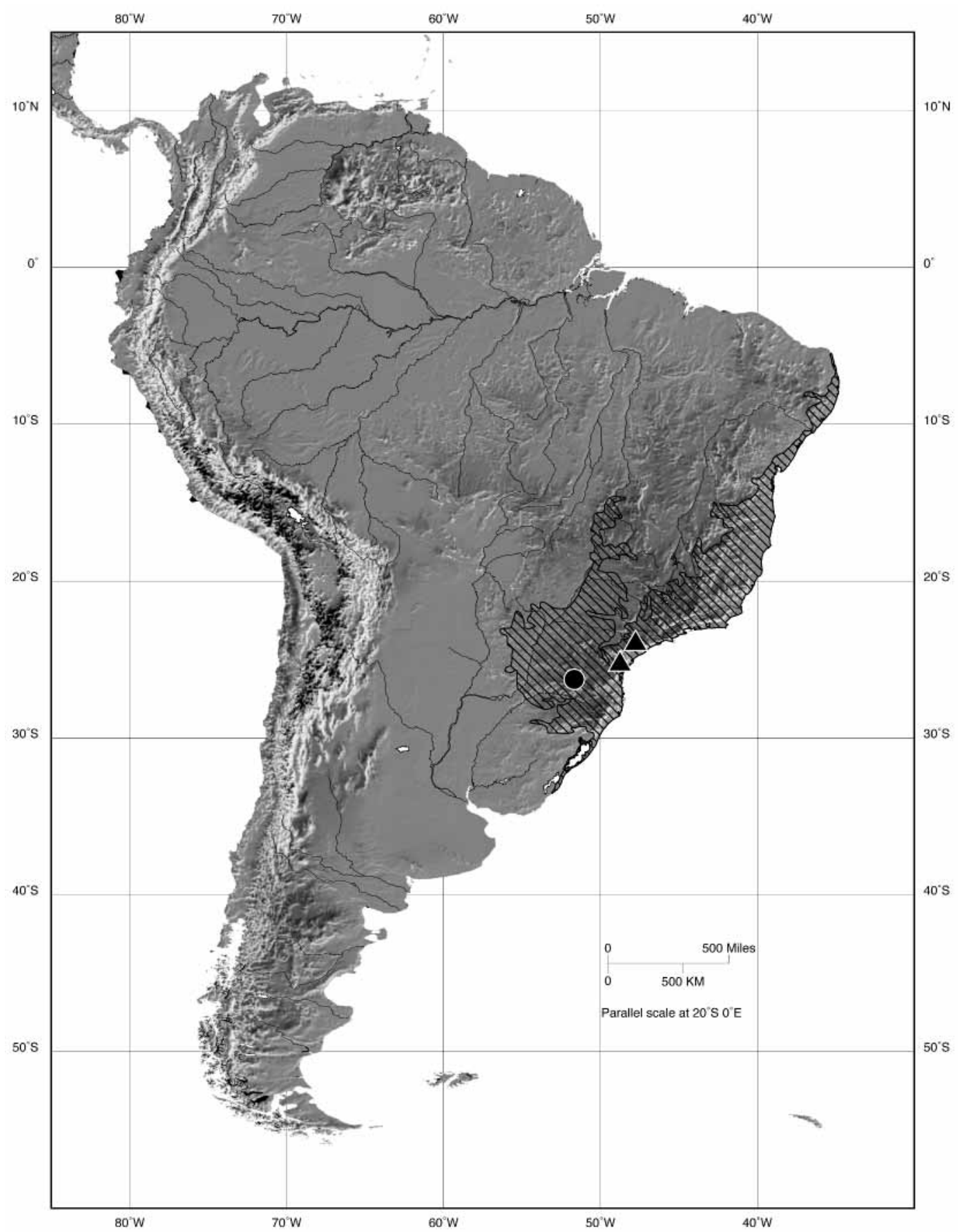

FIGURE 6. Original extent of Atlantic Forest (crosshatch) and distribution of Canoptila. Triangle -Canoptila williami, new species; Circle-Canoptila bifida Mosely. Adapted from Conservation International (www.biodiversityhotspots.org/xp/Hotspots/atlantic_forest/). 
Based on the presence of long spine-like posterolateral processes on tergum $\mathrm{X}$, membranous digitate parameres, and nearly identical wing venation as the type species, this new species is placed in Canoptila.

Holotype male: BRAZIL: São Paulo: Parque Estadual Intervales, Riacho at Poços

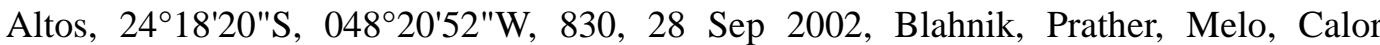
(UMSP000087912) (MZUSP).

Paratypes: Brazil: Parana: Rio Mãe Catira, $10 \mathrm{~km} \mathrm{~N}$ Porto de Cima, 25²1'49"S, 04852'28"W, 200, 8-9.xii.1997, Holzenthal \& Huisman)—2 males, 2 females,(UMSP), 1 male, 1 female (NMNH), 1 male, 1 female (MZUSP).

Distribution. Brazil. This species is known only from the Atlantic Forest in southeastern Brazil.

Etymology. Named in loving memory of William C. Robertson, M.D., the senior author's paternal grandfather.

\section{ACKNOWLEDGMENTS}

We are grateful to Dr. Oliver S. Flint., Jr., Smithsonian Institution, and Mr. David Goodger, Natural History Museum, for generously providing material for examination and inclusion in this study. We thank Dr. Roger J. Blahnik, University of Minnesota, for lively discussions of protoptiline evolution and morphology. Dr. Susan Weller, University of Minnesota, provided helpful suggestions regarding early drafts of this manuscript. Additionally, Dr. Philip J. Clausen, Lourdes Chamorro-Lacayo, Henrique Paprocki, and Anne Wasmund provided assistance throughout this study. We express our appreciation to Dr. Shaun Winterton, Zootaxa associate editor, and 2 anonymous reviewers for their helpful comments. D.R.R. gratefully acknowledges financial support from the Alexander and Lydia Anderson Fellowship, University of Minnesota Graduate School, and the Dayton-Wilkie Natural History Fund, Bell Museum of Natural History, University of Minnesota. This material is based upon work supported by the National Science Foundation grant nos. DEB 9971885 \& 0117772.

\section{REFERENCES}

Angrisano, E.B. (1993) Contribucion al conocimiento del genero Antoptila Mosely (Trichoptera: Glossosomatidae). Revista de la Sociedad Entomologica Argentina, 46, 57-62.

Banks, N. (1904) A list of new Neuropteroid insects, exclusive of Odonata, from the vicinity of Washington, D.C. Proceedings of the Entomological Society of Washinton, 6, 201-217.

Blahnik, R.J. (2005) Alterosa, a new caddisfly genus from Brazil (Trichoptera: Philopotamidae). Zootaxa, 991, 1-60.

Botosaneanu, L. \& Sykora, J. (1973) Sur quelques Trichoptères (Insecta: Trichoptera) de Cuba. In: 

iste România, Bucharest, pp. 379-407.

Burmeister, H. (1839) Handbuch der Entomologie. Zweiter Band, Zweite Ubtheilung, Theodor Christian Friedrich Enslin, Berlin, pp. xii+397-1050.

Flint, O.S., Jr. (1964) The caddisflies (Trichoptera) of Puerto Rico. University of Puerto Rico, Agricultural Experiment Station, Technical Paper, 40, 1-80.

Flint, O.S., Jr. (1967) Studies of Neotropical caddis flies, II: Trichoptera collected by Prof. Dr. J. Illies in the Chilean subregion. Beiträge zur Neotropischen Fauna, 5, 45-68.

da Fonseca, G.A.B. (1985) The Vanishing Brazilian Atlantic Forest. Biological Conservation, 34, $17-34$.

Holzenthal, R.W. (1989) Studies in Neotropical Leptoceridae (Trichoptera), IX: a new genus and species from southeastern Brazil. Aquatic Insects, 11(1), 29-32.

Holzenthal, R.W. \& Andersen, T. (2004) The caddisfly genus Triaenodes in the Neotropica (Trichoptera: Leptoceridae). Zootaxa, 511, 1-80.

Holzenthal, R.W. \& Blahnik, R.J. (2006) The caddisfly genus Protoptila in Costa Rica (Trichoptera: Glossosomatidae). Zootaxa, 1197, 1-37.

Huamantinco, A.A. \& Nessimian, J.L. (2004) A new Neotropical genus and species of Odontoncerinae (Trichoptera: Odontoceridae) from southeastern Brazil. Aquatic Insects, 26(3/4), 281-288.

Morse, J.C. (1975) A phylogeny and revision of the caddisfly genus Ceraclea (Trichoptera: Leptoceridae). Contributions of the American Entomological Institute, 11(2), 1-97.

Morse, J.C. (1988) Protoptila morettii (Trichoptera: Glossosomatidae), a new caddisfly species from the southeastern United States. Rivista di Idrobiologia, 27, 299-308.

Morse, J.C. \& Yang, L. (1993) Higher classification of the Chinese Glossosomatidae (Trichoptera), In: Otto, C. (Ed.), Proceedings of the $7^{\text {th }}$ International Symposium on Trichoptera. Backhuys Publishers, Leiden, The Netherlands, pp. 139-148.

Mosely, M.E. (1934) New exotic Hydroptilidae, Transactions of the Royal Entomological Society of London, 82, 137-163.

Mosely, M.E. (1937) Mexican Hydroptilidae (Trichoptera). Transactions of the Royal Entomological Society of London, 86, 151-190.

Mosely, M.E. (1939) The Brazilian Hydroptilidae (Trichoptera). Novitates Zoologicae, 41, 217-219.

Mosely, M.E. (1954) The Protoptila group of the Glossosomatinae (Trichoptera: Rhyacophilidae). Bulletin of the British Museum (Natural History) Entomology Series, 3(9), 317-346.

Müller, F. (1888) Larven von Mücken und Haarflüglern mit zweierlei abwichselnd thätigen Athemwerkzeugen. Entomologische Nachrichten, 14, 273-277.

Myers, N., Mittermeier, R.A., Mittermeier, C.G., da Fonseca, G.A.B. \& Kent, J. (2000) Biodiversity hotspots for conservation priorities. Nature, 403, 853-858.

Nielsen, A. (1980) A comparative study of the genital segments and the genital chamber in female Trichoptera. Biologiske Skifter, 23(1), 1-200.

Robertson, D.R. \& Holzenthal, R.W. (2005) The Neotropical caddisfly genus Tolhuaca (Trichoptera: Glossosomatidae). Zootaxa, 1063, 53-68.

Ross, H.H. (1956) Evolution and Classification of the Mountain Caddisflies. University of Illinois Press, Urbana, Illinois, 213 pp.

Schmid, F. (1989) Les Hydrobiosides (Trichoptera, Annulipalpi). Bulletin de L'Institut Royal des Sciences Naturelles de Belgique, Entomologie, 59, 1-154.

Schmid, F. (1990) Quelques nouveaux trichoptères indiens (Trichoptera). Naturaliste Canadien, $117,239-251$.

Ulmer, G. (1906) Neuer Beitrag zur Kenntnis aussereuropaeischer Trichopteren. Notes from the Leyden Museum, 28, 1-116. 
Wiggins, G.B. (1996) Trichoptera families. In: Merritt, R.W. \& Cummins, K.W. (Eds.), An Introductions to the Aquatic Insects of North America, $3^{\text {rd }}$ Edition. Kendall/Hunt Publishing Company, Dubuque, Iowa, pp. 309-349. 